\title{
IL-35 induces N2 phenotype of neutrophils to promote tumor growth
}

\author{
Jiu-Ming Zou ${ }^{1, *}$, Jian Qin ${ }^{1, *}$, Yong-Chao Li ${ }^{1}$, Yu Wang ${ }^{1}$, Dong Li ${ }^{1}$, Yu Shu ${ }^{1}$, Chao \\ Luo $^{1}$, Shan-Shan Wang ${ }^{1}$, Gang Chi ${ }^{1}$, Fang Guo ${ }^{1}$, Gui-Mei Zhang ${ }^{1}$, Zuo-Hua Feng ${ }^{1}$ \\ ${ }^{1}$ Department of Biochemistry and Molecular Biology, School of Basic Medicine, Tongji Medical College, Huazhong University \\ of Science and Technology, Wuhan 430030, The People's Republic of China \\ "These authors have contributed equally to this work
}

Correspondence to: Zuo-Hua Feng, email: fengzhg_tj@163.com

Yong-Chao Li, email: yongchaolee@outlook.com

Keywords: IL-35, neutrophils, inflammation, tumor, cytokine

Received: December 08, $2016 \quad$ Accepted: March 24, $2017 \quad$ Published: April 04, 2017

Copyright: Zou et al. This is an open-access article distributed under the terms of the Creative Commons Attribution License (CC-BY), which permits unrestricted use, distribution, and reproduction in any medium, provided the original author and source are credited.

\section{ABSTRACT}

IL-35 is an immunosuppressive cytokine and exerts regulatory effects on T cells, B cells, macrophages and dendritic cells. Neutrophils are important innate immune cells that play key roles in tumor development. The effect of IL-35 on neutrophils remains unknown. Here, we report that IL-35 can induce N2 neutrophil polarization (protumor phenotype) by increasing G-CSF and IL-6 production, and promote neutrophil infiltration into tumor microenvironment. The sustained expression of IL-35 could promote chronic inflammation to augment the proangiogenic and immunosuppressive function of neutrophils. IL-35 stimulated macrophages to secrete proinflammatory cytokines IL-1 $\beta$ and IL-6. IL-1 $\beta$ stimulated $y \delta$ T cells to produce IL17 , which in turn increased the production of G-CSF. By increasing the expression of G-CSF and IL-6, IL-35 could up-regulate the expression of MMP-9 and Bv8, and downregulate TRAIL expression in neutrophils, thus augmenting the proangiogenic function of neutrophils. Moreover, G-CSF/IL-6 induced the enhanced activation of STAT3 and ERK pathways in neutrophils, thus increasing the expression of iNOS to suppress $T$ cell activation. Our findings suggest that IL-35 can promote tumor progression by functioning as an up-stream cytokine to promote cancer-associated inflammation and control neutrophil polarization. Targeting IL-35 might be an important approach for designing new strategy of tumor therapy.

\section{INTRODUCTION}

Inflammation, especially chronic inflammation, is a driving force for tumor initiation and progression. Tumor cells themselves often express some inflammatory cytokines. These inflammatory cytokines play important roles in the processes of cancer-related inflammation [1]. IL-35 is a recently discovered heterodimeric cytokine composed of p35 and EBI3 subunits [2]. Although IL-35 was found as an anti-inflammatory cytokine that inhibits the differentiation of Th17 cells in murine models of autoimmune diseases [3, 4], other studies showed the pro-inflammatory effects of IL-35 in murine models of collagen-induced arthritis and Lyme arthritis $[5,6]$. Importantly, IL-35 has been found to promote tumor progression and metastasis $[7,8]$. Clinical evidences showed that the higher expression of p35 and EBI3 was detected in tumor tissues [9]. The elevated serum IL-35 levels correlated with poor prognosis in patients with renal cell carcinoma and non-small cell lung cancer $[10,11]$. Given that a chronic inflammatory microenvironment is an essential component of all of tumors [1], it is possible that IL-35 may promote tumor development by facilitating chronic inflammation.

Neutrophils are the important components of inflammatory response, which have dual roles in tumor development and metastasis. In response to the stimulation of different cytokines, neutrophils have the potential to polarize towards antitumor (N1) or protumor (N2) phenotypes [12]. In the acute inflammation state, neutrophils are activated to exert antitumor effect. On the contrary, neutrophils are activated by chronic 
inflammation to promote tumor growth and metastasis. The inflammatory cytokines such as G-CSF, IL-6 and TGF- $\beta 1$ can induce N2 phenotype of neutrophils in bone marrow and tumor microenvironment $[13,14]$. In addition, priming with IFN- $\gamma$ and TNF- $\alpha$ can convert the phenotype of neutrophils from N2 to N1 [15]. Thereby, neutrophils may exert either antitumor or protumor function, which mainly depends on regulation of inflammatory cytokines.

A recent report has shown that IL-35 promoted tumor growth and metastasis in Rag1/2-deficient mice that lack $\mathrm{T}$ and $\mathrm{B}$ lymphocytes [16], suggesting that IL-35 may also regulate the innate immune system to promote tumor development. Neutrophils are the most common component of the innate immune system. IL-35 has been demonstrated to possess an immunoregulatory potential on $\mathrm{T}$ and $\mathrm{B}$ lymphocytes $[17,18]$, but the effects of IL-35 on neutrophils remains unknown. In the present study, we investigated whether IL-35 might modulate the polarization of neutrophils to promote tumor progression. Our data showed that IL-35 could function as an up-stream cytokine to promote cancer-associated inflammation, and that IL-35 could induce the polarization of neutrophils towards N2 phenotype, thus facilitating tumor development.

\section{RESULTS}

\section{IL-35 promotes neutrophil infiltration in tumor microenvironment}

To explore the effect of IL-35 on neutrophils in vivo, we fist investigated whether IL-35, as part of its effect on inflammation, may influence neutrophil infiltration in tumor microenvironment. For this purpose, we analyzed the amount of neutrophils in the tumor tissues after the inoculation of tumor cells to naive mice and the mice with in vivo transfection of IL-35 expression vector (IL35-mice). The results showed that the amount of neutrophils in the tumor tissues from IL35-mice was significantly higher than that in the tumor tissues from naive mice (Figure 1A). Consistently, the proportion of neutrophils in blood cells in IL35-mice was significantly increased, compared with that in control mice (Figure 1B), indicating that the in vivo expression of IL-35 promoted the mobilization of neutrophils. Moreover, we also detected the gene expressions of chemoattractants for neutrophils in tumor microenvironment, including CXCL1, CXCL2, CXCL5, CXCL15, CCL2, CCL3, CCL4, CCL5 and VEGF [19-21]. The results showed that several genes were highly expressed in tumor, including $\mathrm{Cxcl}, \mathrm{Ccl} 2$, Ccl3, Ccl4, and Ccl5 (Figure 1C). These results suggested that IL-35 might promote the infiltration of neutrophils by increasing circulating neutrophils, based on the expression of multiple chemoattractants for neutrophils in tumor microenvironment.

To further ascertain the effect of IL-35, we inoculated the mice with B16F0 cells expressing IL-
35 (B16-IL35), or inoculated the mice with $\mathrm{H} 22$ cells followed by local transfection of pIL-35 to express IL35 in tumor microenvironment. Consistent with the above results, the increase of local IL-35 expression in tumor promoted the growth of tumor and the infiltration of neutrophils (Supplementary Figure 1A and 1B).

\section{IL-35 switches the function of neutrophils toward tumor-promoting}

We next investigated the effect of IL-35 on the function of neutrophils in vivo by recruiting neutrophils to the tissues at the inoculation site in naive mice and IL35-mice. The recruitment of neutrophils suppressed the growth of tumor in naive mice, but significantly promoted tumor growth in IL35-mice (Figure 2A), suggesting that IL-35 could induce the conversion of neutrophil function in vivo. To further confirm this, we isolated neutrophils from bone marrow of mice to test their function. In coinoculation test, the neutrophils from IL35-mice indeed significantly promoted the growth of tumor (Figure 2B). To ascertain that the protumor function of neutrophils could be maintained after the process of chemotaxis, we isolated neutrophils from peritoneal cavity of mice after recruitment, and tested their function in co-inoculation test. The results showed that the neutrophils from naive mice suppressed the growth of tumor, but the neutrophils from IL35-mice promoted tumor growth (Figure 2C). Taken together, these results indicated that the sustained expression of IL-35 in vivo could induce the conversion of neutrophil function from tumor-suppressing to tumor-promoting.

\section{IL-35 augments proangiogenic and immunosuppressive function of neutrophils in vivo}

Neutrophils with protumor phenotype could promote tumor development by promoting tumor angiogenesis and suppressing immune response [22, 23]. To further ascertain the conversion of neutrophil function, we analyzed the effect of IL-35 on the proangiogenic and immunosuppressive function of neutrophils. The results showed that neutrophils from IL35-mice could significantly promote tumor angiogenesis (Figure 3A). Similar results were obtained when IL-35 was expressed in tumor microenvironment (Supplementary Figure 1C). Consistently, the sustained expression of IL-35 in vivo resulted in up-regulation of expression levels of MMP9 and Bv8 that promote angiogenesis, and the downregulation of TRAIL that suppresses angiogenesis in neutrophils (Figure 3B and Supplementary Figure 2A, 2B).

We then analyzed whether IL-35 might augment the immune suppressive function of neutrophils. When splenic cells were stimulated with $\mathrm{CD} 3 / \mathrm{CD} 28$ antibodies in the presence of neutrophils, $\mathrm{T}$ cell proliferation was not significantly suppressed by the neutrophils from 
naive mice. However, the neutrophils from IL35-mice significantly suppressed $\mathrm{T}$ cell proliferation (Figure 3C and Supplementary Figure 2C), indicating that the sustained expression of IL-35 significantly augmented the immunosuppressive function of neutrophils. Neutrophils have been known to produce arginase 1 (Arg-1) and inducible nitric oxide synthase (iNOS) to suppress $\mathrm{T}$ cell antitumor immune response [24-26]. Arg-1 was involved in the inhibitory effect of neutrophils from naive mice, since the effect could be abolished by arginase- 1 inhibitor,
A

$\mathrm{H} 22$
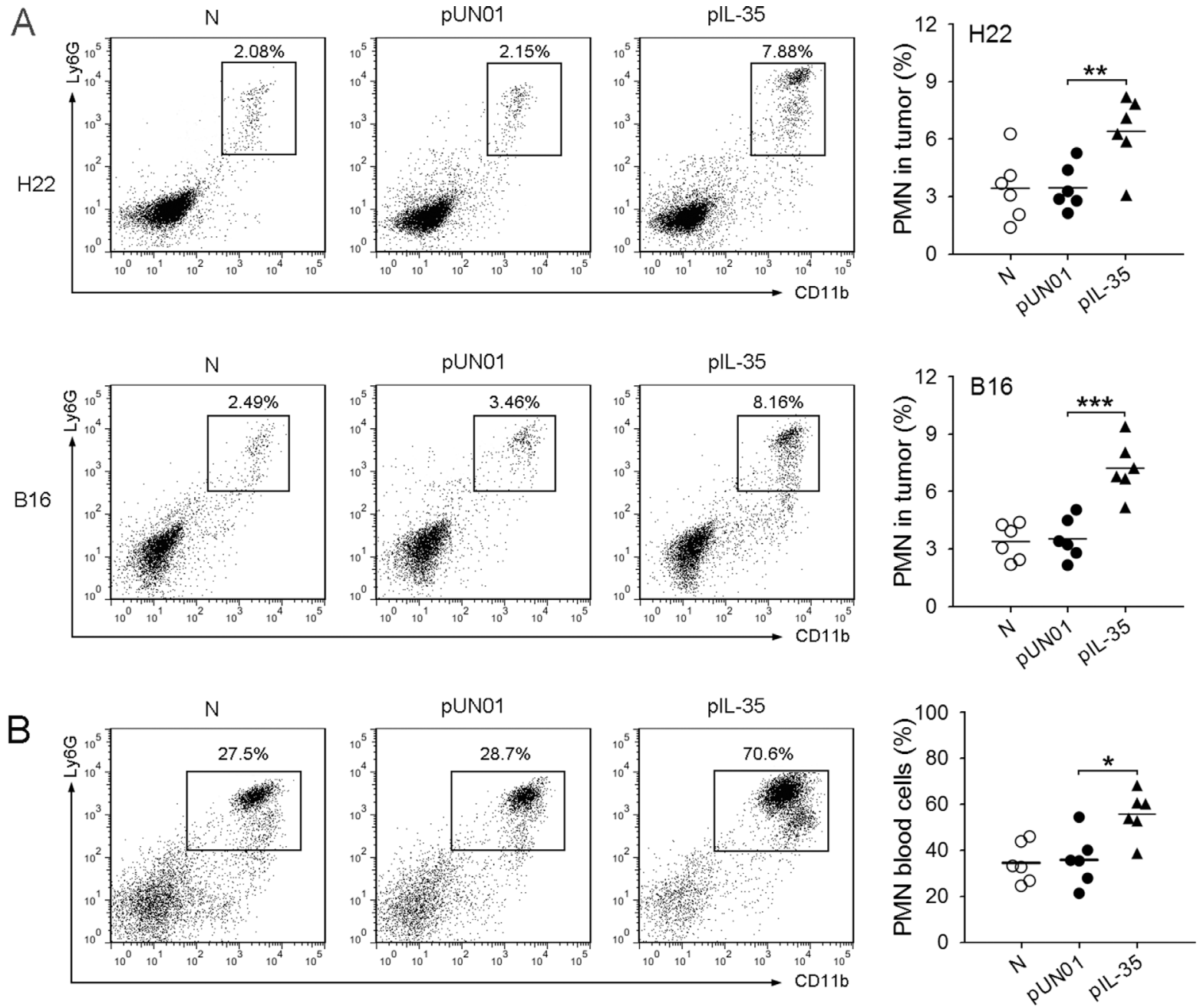
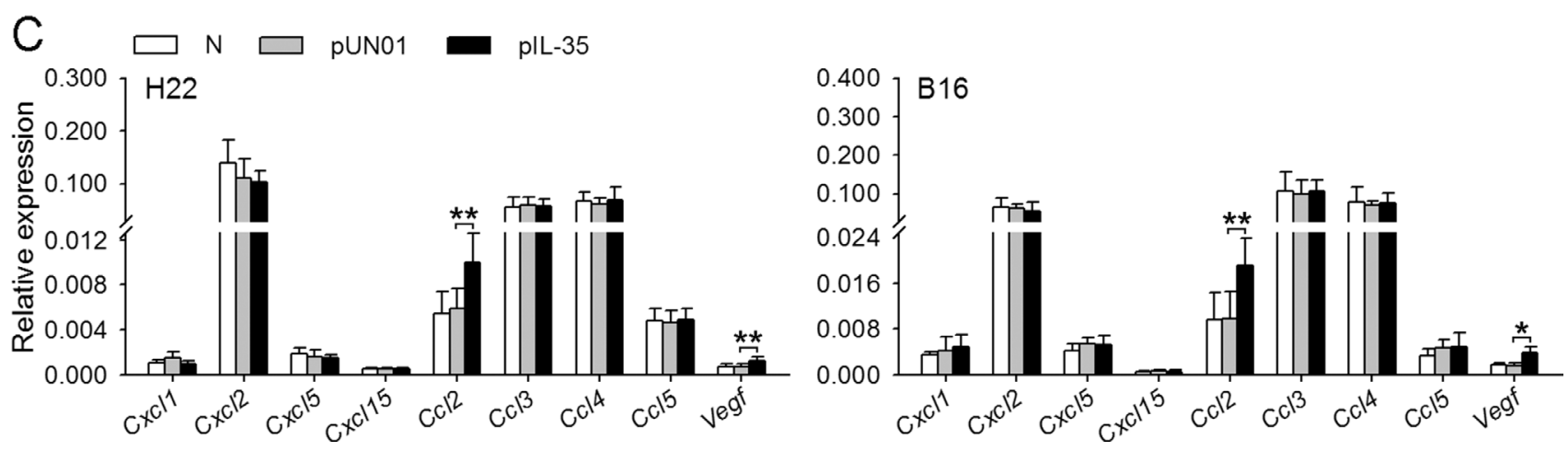

Figure 1: IL-35 promotes neutrophil infiltration in tumor microenvironment. (A) Tumor cells were intramuscularly injected to the right hind thigh of naive mice $(\mathrm{N})$, pUN01-mice and pIL-35-mice. The plasmid injection was continued after tumor cell inoculation, once every two days. Tumors were dissected on day 10 after tumor cell inoculation. Neutrophils in tumor tissues were analyzed by flow cytometry. (B) Flow cytometric analysis of neutrophils in peripheral blood of naive mice, pUN01-mice, and pIL-35-mice. (C) In the experiments same as (A), the expression of Cxcl1, Cxcl2, Cxcl5, Cxcl15, Ccl2, Ccl3, Ccl4, Ccl5, and Vegf genes in tumor tissues was detected at the mRNA level by real-time RT-PCR. Data are pooled from three independent experiments with a total six samples in each group. ${ }^{*} p<0.05, * * p<0.01, * * * p<0.001$. 

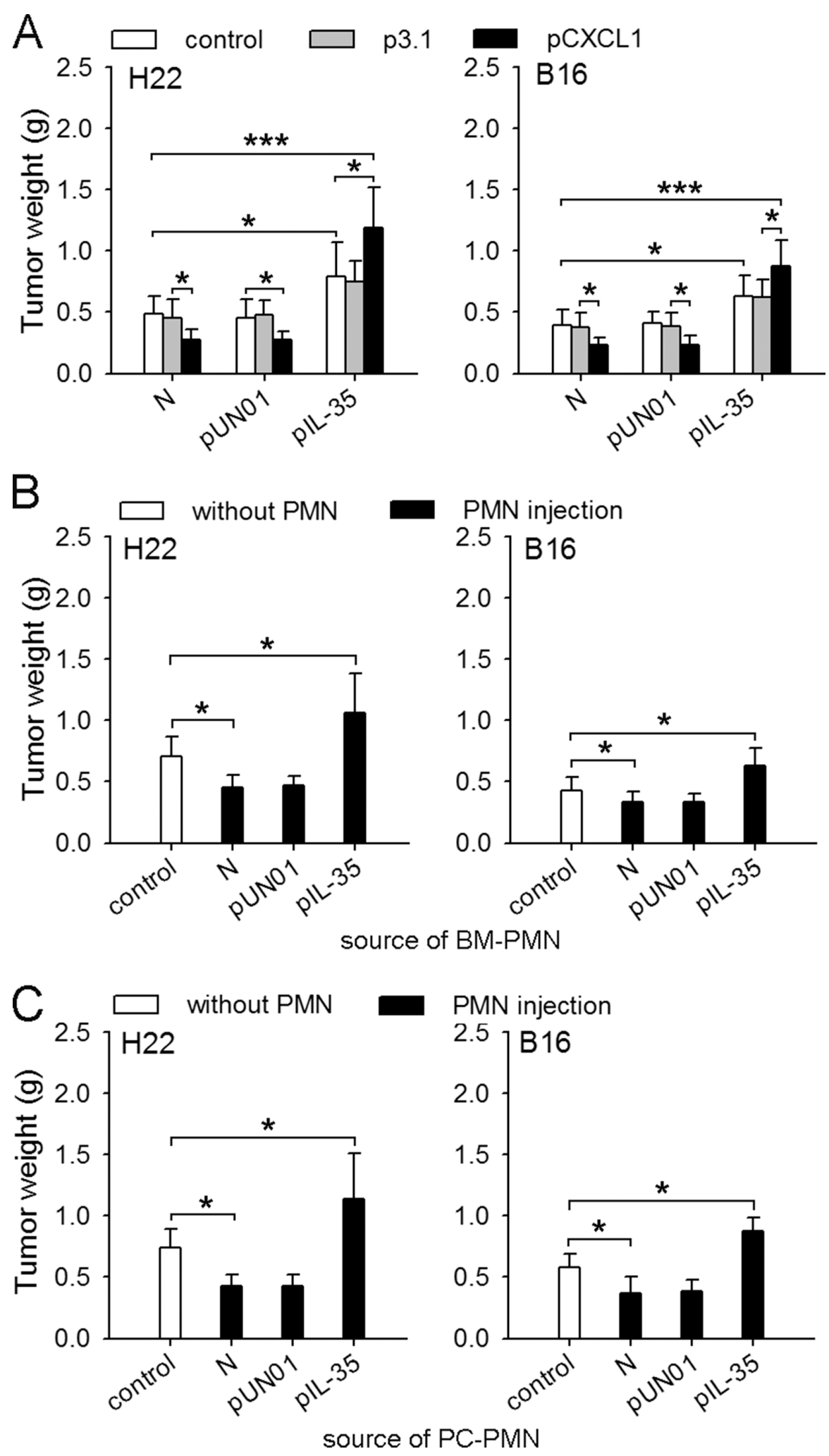

Figure 2: IL-35 switches the function of neutrophils toward tumor-promoting. (A) H22 or B16 cells were inoculated into naive mice, pUN01-mice, and pIL-35-mice. CXCL1 was expressed in local tissues to recruit neutrophils, as described in Methods. The effect of neutrophil recruitment on tumor growth was evaluated by measuring tumor weight. (B and $\mathbf{C})$ Neutrophils were isolated from bone marrow (BM) or peritoneal cavity (PC) of naive mice, or pUN01-mice and pIL-35-mice. The neutrophils from BM (B) or PC (C) were used for co-inoculation test as described in Methods. Tumors ( $n=9$ per group) were dissected and weighed on d10 after tumor cell inoculation. $* p<0.05, * * p<0.01, * * * p<0.001$. 
norNOHA (Figure 3C). Intriguingly, IL-35-augmented suppressive function of neutrophils was abrogated by iNOS inhibitor, L-NMMA (Figure 3C), suggesting that IL-35 could augment the immunosuppressive function of neutrophils by increasing the expression of iNOS. To further confirm this, we analyzed the expression of $\mathrm{Arg} 1$ and Nos 2 genes. In the neutrophils from naive mice, the expression of Arg-1, but not iNOS, was detectable (Supplementary Figure 2D). In the neutrophils from IL35-mice, the expression of iNOS, but not Arg-1, was significantly increased (Figure 3D and Supplementary Figure 2D), suggesting that IL-35 could augment the immunosuppressive function of neutrophils by increasing iNOS expression.

\section{G-CSF/IL-6 but not IL-35 directly alters the function of neutrophils}

Next, we wondered whether IL-35 could directly induce the conversion of neutrophil function. To clarify this, we isolated neutrophils from naive mice, and stimulated the cells with recombinant mouse IL-35. Unexpectedly, the stimulation with IL-35 did not influence the expression of Mmp 9, Bv8, Trail, Nos2, and Arg1 genes in neutrophils (Figure 4A), suggesting that IL-35 could not directly induce the conversion of neutrophil function. Our previous study showed that G-CSF and IL-6 could up-regulate the expression of $M m p 9$ and $B v 8$, and downregulate the expression of Trail [13]. Interestingly, G-CSF/ IL-6 not only modulated the expression of these genes, but also significantly increased the expression of Nos 2 gene (Figure 4A). Both G-CSF and IL-6 alone could induce the expression of Nos 2 gene, and cooperatively induce higher expression of Nos 2 by directly stimulating neutrophils (Figure 4B). Likewise, in vivo transfection of G-CSF and IL-6 expression vectors enhanced the expression level of Nos2 gene in bone marrow neutrophils (Figure 4C).

\section{Enhanced activation of STAT3 and ERK pathways is required for upregulating iNOS}

Our previous study showed that G-CSF/IL-6 could modulate the expression of $M m p 9, B v 8$, and Trail by inducing the enhanced activation of STAT3 pathways [13]. Here we further investigated the mechanism underlying the up-regulation of Nos 2 gene. It has been reported that the expression of iNOS in neutrophils could be regulated by several signaling pathways, including p38 MAPK, JNK, ERK [27, 28]. However, G-CSF mainly activates the STAT3, PI3K, and ERK pathways in neutrophils $[29,30]$. IL-6 also activates STAT3 pathway [31]. We therefore stimulated neutrophils with G-CSF and/or IL-6 in the presence of wortmannin (PI3K inhibitor), PD98059 (inhibitor of ERK pathway), or STAT3 inhibitor VIII. The results showed that Nos2 gene expression was suppressed in the presence of STAT3 inhibitor VIII, when neutrophils were stimulated by G-CSF and/or IL-6 (Figure 5A and Supplementary Figure 3). Inhibiting ERK pathway with PD98059 could partially inhibit Nos 2 gene expression in the presence of G-CSF, but inhibiting PI3K pathway with wortmannin did not influence the expression of Nos2 gene. These results indicated that STAT3 and ERK pathways were involved in G-CSF/IL-6-induced expression of Nos2 gene. Consistently, the phosphorylation levels of STAT3 and ERK1/2 in the neutrophils from IL35-mice were significantly higher than those in the neutrophils from naive mice (Figure 5B, 5C).

\section{IL-35 increases G-CSF and IL-6 production in vivo}

The above results suggested that IL-35 might modulate gene expression in neutrophils by inducing the expression of G-CSF and IL-6. To ascertain this, we investigated whether IL-35 might influence the in vivo expression of G-CSF, IL- 6 and TGF- $\beta$ that are able to regulate the function of neutrophils. After the sustained expression of IL-35, the expression levels of Gcsf and Il6 mRNAs, but not $T g f b 1$ mRNA, were significantly increased in the spleen, lung and bone marrow of mice (Figure 6A). Consistently, IL-35 induced the persistently low and steady levels of G-CSF and IL-6 in blood (Figure 6B).

\section{IL-35 stimulates macrophages to produce IL-6 but not G-CSF}

A recent study showed that recombinant human IL-35 cytokine could stimulate peripheral blood mononuclear cells (PBMCs) to produce IL-6 and IL-1 $\beta$ [32]. IL-6 could be produced by macrophages and the activated $\mathrm{T}$ lymphocytes [33]. Macrophages were also an important source of IL-1 $\beta$ and G-CSF [24, 34]. Thus, we prepared macrophages from the naive mice, and detected the expression of IL-6, IL-1 $\beta$ and G-CSF after the stimulation with IL-35. The results showed that IL35 dose-dependently induced the expression of IL- 6 and IL-1 $\beta$, but not G-CSF (Figure 7), suggesting that IL-35 could directly stimulate macrophages to produce IL-6, but induce the G-CSF production in vivo in a different way.

\section{Macrophages/IL-1 $\beta / \gamma \delta \mathrm{T}$ cells/IL-17 axis is involved in IL-35-induced expression of G-CSF in vivo}

It has been known that IL-17A could induce the production of G-CSF in vivo [24]. Interestingly, IL-17A level in the blood of IL35-mice was much higher than that in the blood of naive mice (Figure 8A). In addition to IL-6, the increase of IL-35 expression in tumor could increase IL-17A and G-CSF in blood and tumor microenvironment (Supplementary Figure 4). We therefore investigated 
whether IL-35 might induce G-CSF expression in vivo by increasing IL-17A expression by neutralizing IL-17A in vivo. Indeed, the neutralization of IL-17A in vivo suppressed the production of G-CSF in IL35-mice (Figure 8B). CD4 ${ }^{+}$Th17 cells and $\gamma \delta \mathrm{T}$ cells are two populations that produce IL-17A [35]. Recent studies showed that IL-1 $\beta / \gamma \delta$
T cells axis was important regulatory pathway of IL-17A [24]. In IL35-mice, the frequency of IL-17A-producing $\mathrm{CD}^{+}$Th17 cells in spleen was not significantly changed (Supplementary Figure 5), but the serum level of IL-1 $\beta$ was significantly increased (Figure $8 \mathrm{C}$ ), suggesting that $\gamma \delta$ T cells might be the source of IL-17A in presence of
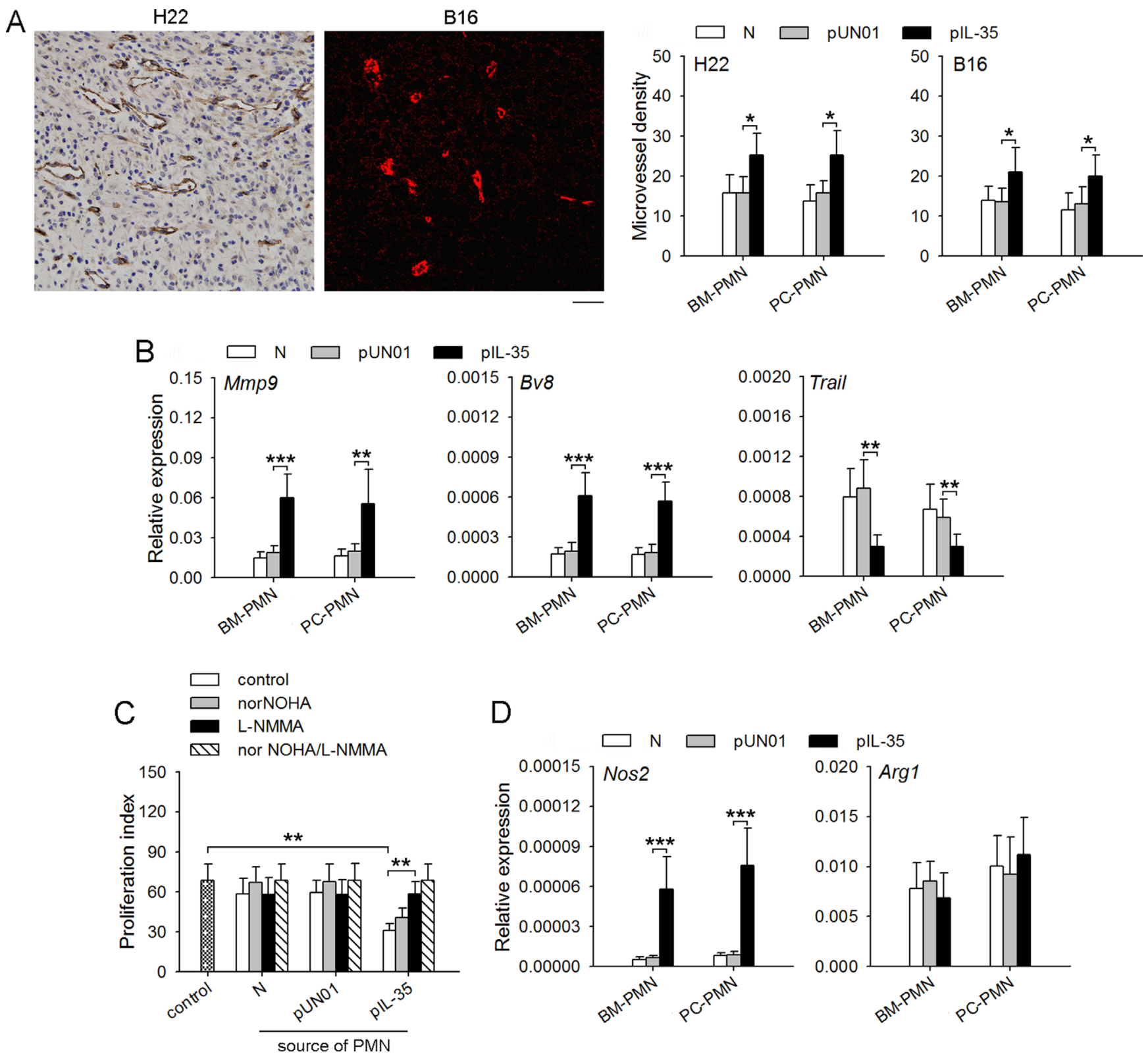

Figure 3: IL-35 augments proangiogenic and immunosuppressive function of neutrophils in vivo. (A) Neutrophils were isolated from bone marrow (BM) or peritoneal cavity (PC) of naive mice, pUN01-mice, and pIL-35-mice. The neutrophils were injected into palpable tumors. Microvessels in tumor tissues were detected by immunohistochemical analysis (left, scale bar, 50 um). Microvessel density was determined as described in Methods (right). (B) Neutrophils were isolated from bone marrow or peritoneal cavity of naive mice, pUN01-mice, and pIL-35-mice. The expression of Mmp-9, Bv8, and Trail genes in BM and PC neutrophils were detected by real-time RT-PCR. (C) CFSE-labeled splenocytes from naive mice were incubated with CD3/CD28 stimulation beads in the absence or presence of the neutrophils isolated from bone marrow of naive mice, pUN01-mice and pIL-35-mice. NorNOHA and L-NMMA were added as indicated. After 48-h culture, splenocyte proliferation was measured as described in Methods. (D) Neutrophils were isolated from bone marrow or peritoneal cavity of naive mice, pUN01-mice, and pIL-35-mice. The expression of Nos2 and Arg1 genes in neutrophils were detected by real-time RT-PCR. Data are pooled from three independent experiments with a total six samples in each group. $* p<0.05$, $* * p<0.01, * * * p<0.001$. 
IL-35. In line with this, depleting $\gamma \delta \mathrm{T}$ cells (Figure 8D) or neutralizing IL-1 $\beta$ (Figure $8 \mathrm{E}$ ) in vivo could abrogate the increased expression of both G-CSF and IL-17A in IL35-mice. Taken together, these results suggest that macrophages/IL- $1 \beta / \gamma \delta$ T cells/IL-17 axis is involved in IL35-induced expression of G-CSF in vivo.

\section{DISSCUSION}

High expression of IL-35 in tumor tissues and the elevated plasma IL-35 levels have been reported in patients with solid or hematopoietic malignancy $[10,11,36]$. The increase of IL-35 in tumor could promote tumor progression as shown by our data and others [37]. Moreover, our data also showed that the increase of IL-35 in blood resulted in N2 polarization of neutrophils, thus promoting tumor progression. IL-35 could function as an up-stream cytokine to control neutrophil polarization by inducing the production of other cytokines. Although IL-35 might not be the only cytokine that induces the conversion of neutrophil function from tumor-suppressing to tumor-promoting, the increase of IL-35 in tumor and blood could certainly promote the tumor-promoting function of neutrophils.

Neutrophils, as an important population of inflammatory cells, may have different phenotypes in different inflammatory disorders. Acute inflammation induces N1 neutrophils to eliminate pathogens, whereas chronic inflammation induces N2 neutrophils to promote angiogenesis and tissue remodeling. During tumor progression, N2 neutrophils could fuel both primary tumor growth and tumor metastasis [12]. Our data showed that IL-35 could induce the N2 phenotype of neutrophils by inducing the conversion of neutrophil function from tumor-suppressing to tumor-promoting. After the sustained expression of IL-35 in vivo, neutrophils produced more MMP-9 and Bv8 that promote tumor angiogenesis $[38,39]$ and iNOS that inhibits $\mathrm{T}$ cell activation, but expressed much less TRAIL that induces tumor cell apoptosis and inhibits angiogenesis [40, 41]. Therefore, in tumor-associated inflammation, IL-35 could be a crucial cytokine that controls the polarization of neutrophils.

IL-35 could not directly stimulate neutrophils to induce their functional conversion as shown by our data. Instead, the sustained IL-35 expression in vivo increased the production of G-CSF and IL-6. Our previous study showed that G-CSF and IL-6 can induce the conversion of neutrophil function from tumor-suppressing to tumor-promoting [13]. IL-6 cooperates with G-CSF to induce the sustained and enhanced activation of STAT3, thus up-regulating the expression of MMP-9 and Bv8, but down-regulating TRAIL expression in neutrophils [13]. In this study, we
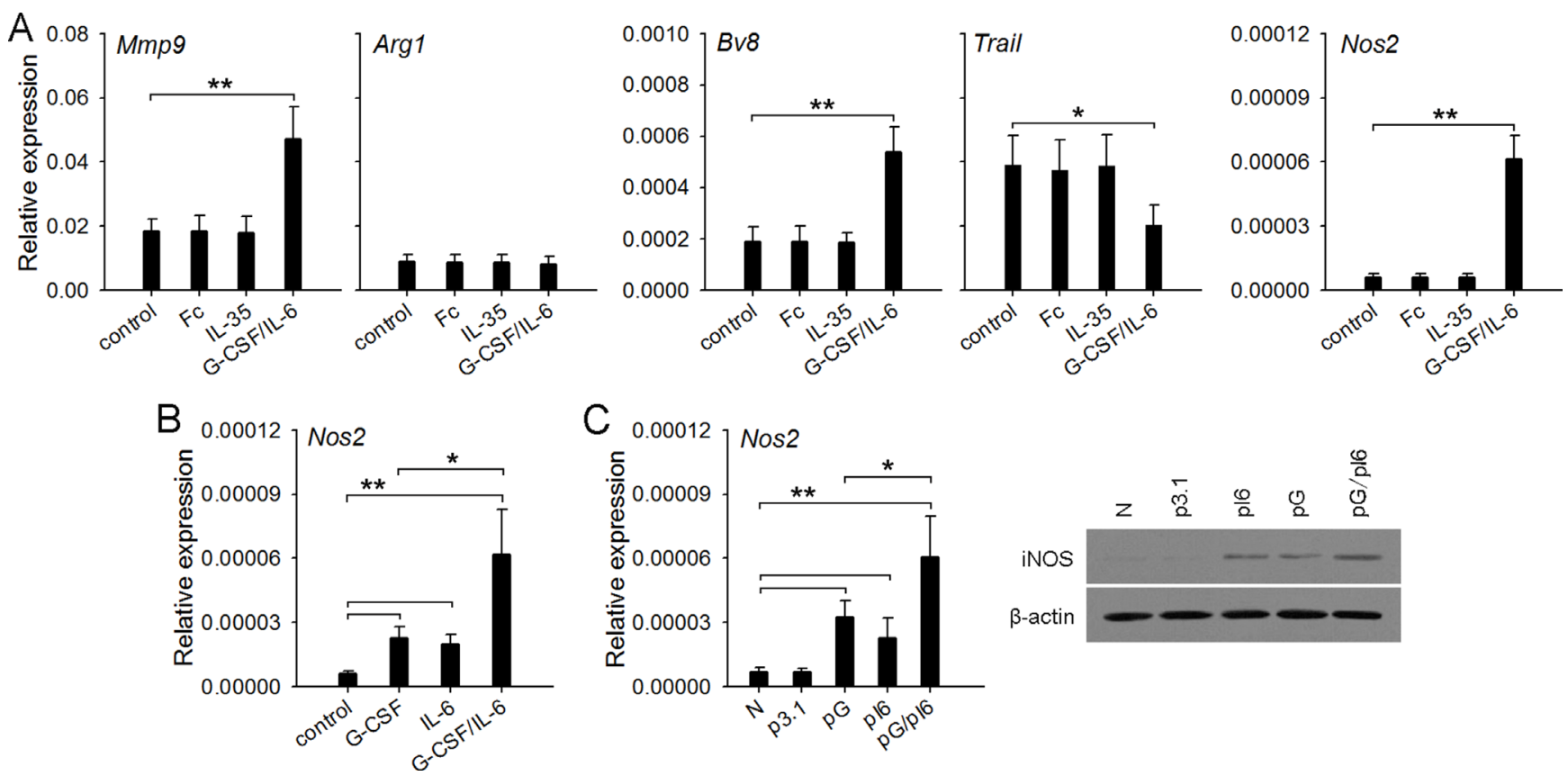

Figure 4: G-CSF/IL-6 but not IL-35 directly alters the function of neutrophils. (A) Neutrophils were isolated from naive mice and cultured $\left(2 \times 10^{6} / \mathrm{ml}\right)$ in 6 -well flat bottom plate $(2 \mathrm{ml} /$ well $)$ in the absence or presence of IL-35 (100 ng/ml, or G-CSF/IL-6 (50 ng/ml of each). After 12-h culture, gene expressions were detected by real-time PCR. The IgG Fc fragment (Fc) was using as control for excluding any nonspecific effect of recombinant protein. (B) Neutrophils were isolated from bone marrow of naive mice, and cultured in the absence or presence of G-CSF and/or IL-6 (50 ng/ml of each). After 12-h culture, the expression of Nos2 gene was detected. (C) Neutrophils were isolated from $\mathrm{BM}$ of naive mice, p3.1-mice, pG-mice, pI6-mice, and pG/pI6-mice. The expression of Nos 2 gene in neutrophils was detected by real-time RT-PCR and western blots. Data are representative of three independent experiments (C, right), or are pooled from three independent experiments with a total six samples in each group (A-C). ${ }^{*} p<0.05,{ }^{* *} p<0.01,{ }^{* * *} p<0.001$. 
further demonstrated that G-CSF and IL-6 could upregulate the expression of iNOS that contributes to the survival and proliferation of tumor cells by suppressing $\mathrm{T}$ cell activation. ERK and STAT3 pathways were crucial for G-CSF to induce iNOS expression in neutrophils. IL-6 induced the expression of iNOS by activating STAT3. IL-6 cooperation with G-CSF could further increase the expression of iNOS. Moreover, our data in this study further confirmed that the enhanced STAT3 activation is crucial for tumor-promoting function of neutrophils. In line with the promoting effect of IL-35 on G-CSF/IL-6 production in vivo, the sustained expression of IL-35 could enhance the activation of STAT3 and ERK pathways in neutrophils. In this regard, the increased production of G-CSF/IL-6 is crucial for IL-35 to induce the $\mathrm{N} 2$ phenotype of neutrophils in vivo.
G-CSF and IL-6 could be produced by several types of cells in vivo. In this study, we demonstrated that macrophages were involved in IL-35-induced production of G-CSF and IL-6 in vivo. In response to IL-35 stimulation, IL-6 expression was directly induced in macrophages. Different from the expression of IL6 , the expression of G-CSF in vivo was induced by IL35 through an indirect way. IL-17A has been known to induce the production of G-CSF in vivo [42]. Although IL-35 could suppress the differentiation of Th17 cells that produce IL-17A [3], our data showed that IL-35 could promote the expression of IL-17A in vivo. In this situation, IL-35 induced the expression of IL-17A in $\gamma \delta$ T cells, since IL-35-induced expression of IL-17A could be suppressed by depleting $\gamma \delta$ T cells. In the presence of
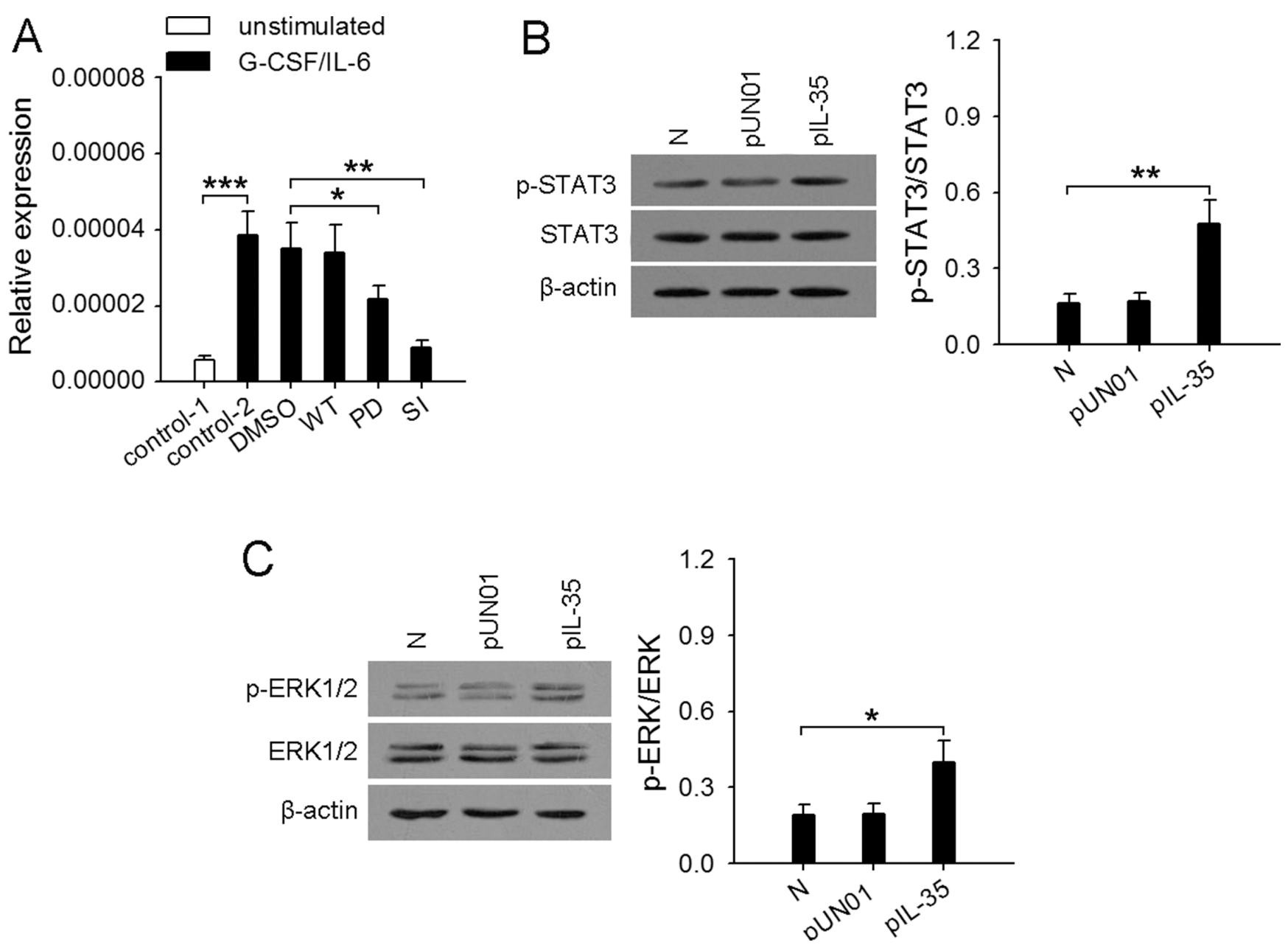

Figure 5: Enhanced activation of STAT3 and ERK pathways in neutrophils is required for the upregulation of iNOS. (A) Neutrophils were isolated from bone marrow of naive mice. The cells $\left(2 \times 10^{6} / \mathrm{ml}\right)$ were untreated or pretreated for $2 \mathrm{~h}$ with STAT3 inhibitor VIII (SI, $50 \mu \mathrm{M}$ ), wortmannin (WT, $10 \mathrm{nM}$ ), PD98059 (PD, $20 \mu \mathrm{M}$ ), and then stimulated for $12 \mathrm{~h}$ with or without G-CSF/IL-6 $(50 \mathrm{ng} / \mathrm{ml}$ of each) in the absence or presence of the same inhibitor. The expression of Nos 2 gene was detected at the mRNA level by realtime RT-PCR. (B and C) Neutrophils were isolated from bone marrow of naive mice, pUN01-mice, and pIL-35-mice. The phospho-STAT3 (p-STAT3) and total STAT3 (B), phospho-Erk1/2 (p-Erk1/2) and total Erk1/2 (C) in neutrophils were detected by Western blot. The ratios of (p-STAT3/STAT3) or (p-ERK/ERK) were calculated after densitometric analysis of Western blots. Data are representative of three independent experiments $\left(\mathrm{B}\right.$, left; $\mathrm{C}$, left), or pooled from three independent experiments with a total six samples in each group. ${ }^{*} p<0.05$, $* * p<0.01$. 
tumor, $\gamma \delta$ T cells, rather than Th17 cells, were predominant source of IL-17A [24]. Our data showed that IL-35 could induce the expression of IL- $1 \beta$ in macrophages, and that IL-1 $\beta$ further elicited the production of IL-17A from $\gamma \delta$ $\mathrm{T}$ cells in vivo. Either blocking IL-1 $\beta$ or depleting $\gamma \delta \mathrm{T}$ cells could efficiently suppress IL-35-induced expression of G-CSF in vivo. Our data did not rule out the possibility that some other types of cells might be involved in IL-35induced production of G-CSF/IL-6 in vivo. Nevertheless, our data clearly demonstrated that IL-35 could directly stimulate macrophages to produce IL-6, and induce G-CSF production through macrophages/IL- $1 \beta / \gamma \delta$ T cells/ IL-17 axis.

High neutrophil numbers in the circulation in patients is associated with poor overall survival [43]. Our data showed that IL-35 could increase the proportion of neutrophils in peripheral blood. It is well known that G-CSF promotes myelopoiesis and mobilization of bone marrow neutrophils [42], which might be the main reason that IL-35 could increase the amount of neutrophils in blood circulation. In addition, IL-35 could also promote neutrophil infiltration in tumor microenvironment. As shown in our data, the genes of several chemoattractants for neutrophils were highly expressed in tumor, including $\mathrm{Cxcl}$, Ccl2, Ccl3, Ccl4, and Ccl5. In addition to Ccl2, the expression of these genes was not influenced by IL-35. Therefore, IL-35 might mainly promote the infiltration of neutrophils by increasing circulating neutrophils, based on the expression of multiple chemoattractants for neutrophils in tumor microenvironment.

During the development of tumor, IL-35 could be produced by not only tumor cells but also stroma cells and immune cells $[44,45]$. Intriguingly, our data in this study showed that IL-35 could function as an up-stream cytokine to promote cancer-associated inflammation. The functional conversion of neutrophils is directly induced by G-CSF and IL-6. Importantly, the in vivo production of G-CSF and IL- 6 could be augmented by IL-35. The sustained expression of IL-35 determines the conversion of neutrophil function from tumor-suppressing to tumor-promoting. Given that the protracted depletion of neutrophils is clinically untenable, targeting IL-35 might be very important for designing the therapeutic strategy to prevent the tumor-promoting effect of neutrophils.

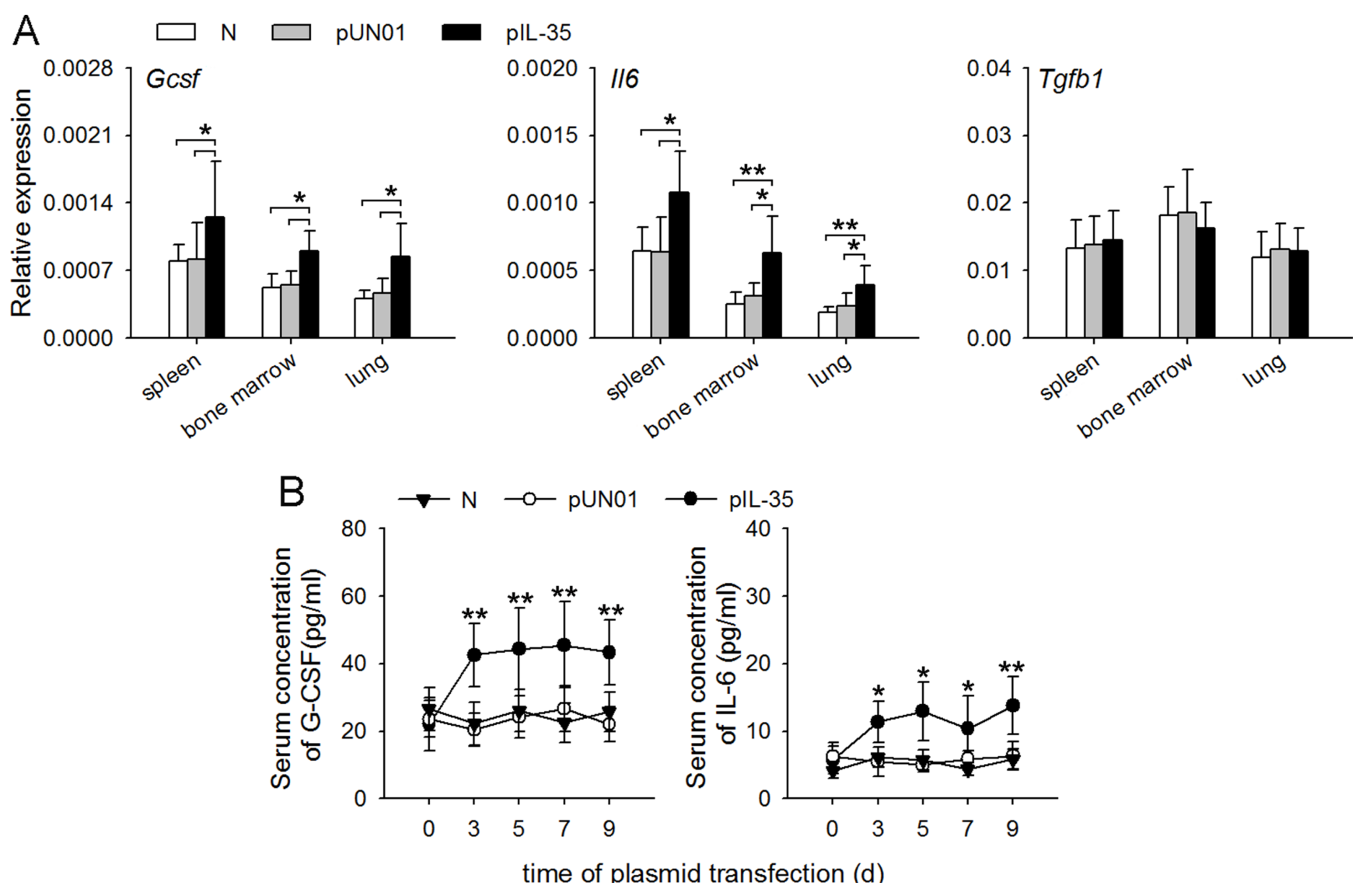

Figure 6: IL-35 increases G-CSF and IL-6 production in vivo. (A) The expressions of Gcsf, Il6 and $T g f b 1$ genes in the indicated organs of naive mice, pUN01-mice, and pIL-35-mice were detected by real-time RT-PCR. (B) Mice were untreated or received i.m. injection of pIL-35 plasmid or pUN01 plasmid. Then, the G-CSF and IL-6 levels in serum of mice were detected by ELISA at the indicated time point. Data are pooled from three independent experiments with a total six samples in each group. ${ }^{*} p<0.05, * * p<0.01$. 

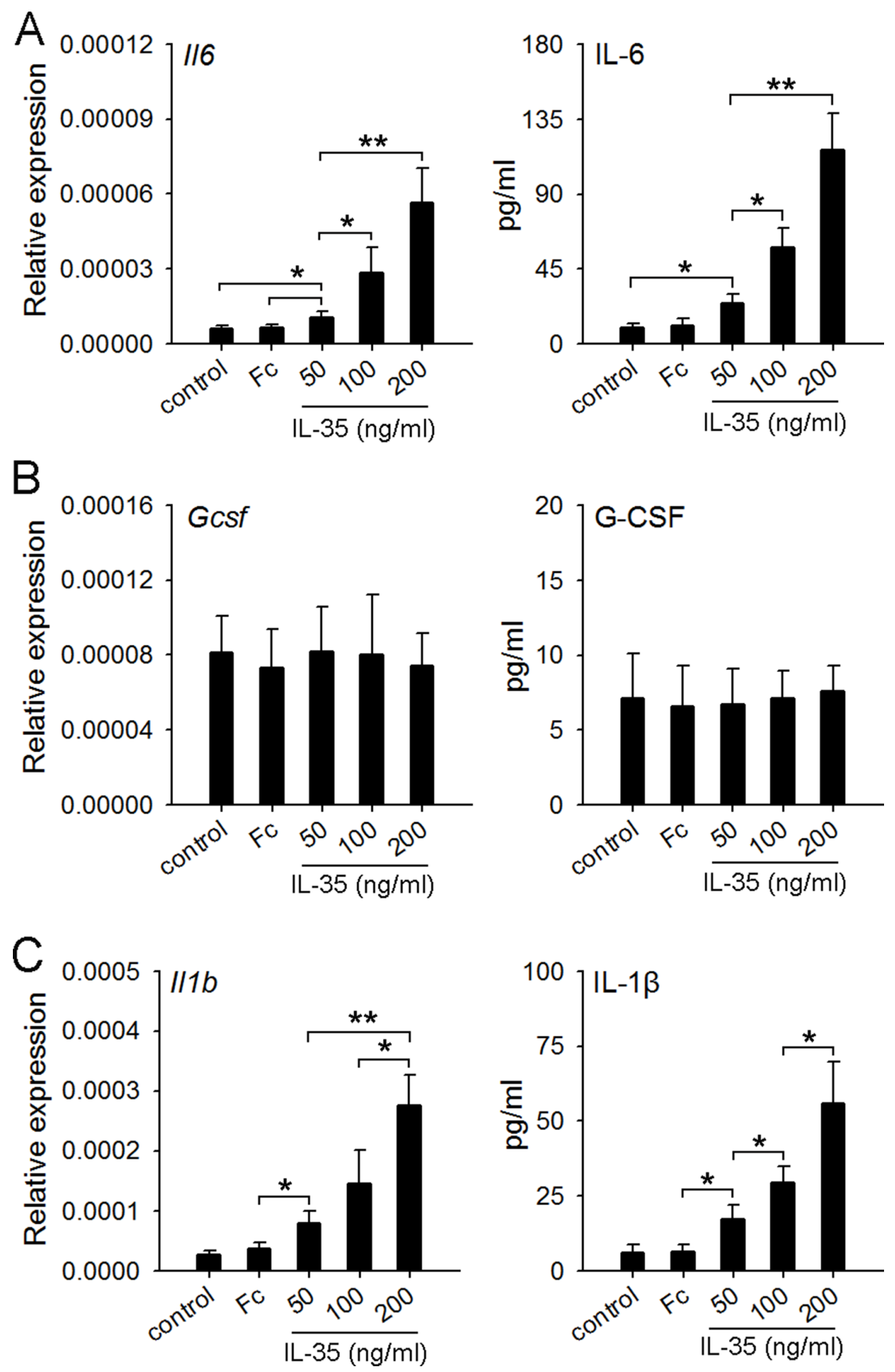

Figure 7: IL-35 stimulates macrophages to produce IL-6 but not G-CSF. (A-C) Macrophages were prepared from naive mice as described in Methods. The cells were then cultured in the absence or presence of IL-35 at the indicated concentration. IgG Fc fragment (Fc) was used as control. After 12-h culture, the expressions of $I l 6(\mathrm{~A})$ Gcsf (B) and $I l 1 b$ (C) genes were detected by real-time PCR. The levels of IL-6, G-CSF and IL-1 $\beta$ in culture supernatants were detected by ELISA. Data are pooled from three independent experiments with a total six samples in each group. ${ }^{*} p<0.05, * * p<0.01$. 


\section{MATERIALS AND METHODS}

\section{Animals and cell lines}

Female BALB/c mice and $\mathrm{C} 57 \mathrm{BL} / 6$ mice aged 6 to 8 weeks were purchased from the center of Medical Experimental Animals of Hubei Province (Wuhan, China). The mice were maintained in the accredited animal facility of Tongji Medical College, and animal care was in accordance with institutional guidelines. All animal experiments were approved by the Committee on the Ethics of Animal Experiments of Tongji Medical College (Permit Number: 2014-S514). The BALB/c background H22 hepatocarcinoma cell line and C57BL/6 background B16F0 melanoma cells were purchased from the China Center for Type Culture Collection (Wuhan, China) and cultured according to their guidelines.

\section{Reagents and plasmids}

Murine rIL-35:Fc fusion protein was purchased from Chimerigen Laboratory (AdipoGen life science).
The recombinant fusion protein possesses high stability and long circulating half-life owing to the extracellular domain of mouse IL-12a subunit is fused to the Fc region of human IgG1, and the mouse EBI3 subunit linked to IL12 a by disulfide bonds. Plasmid pIL-35 is the expression vector that expresses a "native" form of IL-35 made of IL12a and Ebi3 linked subunits. pIL-35 (pUN01 IL-35 elasti) was purchased from Invivogen. Plasmid pUN01 was also purchased and used as control plasmid. Plasmids pGCSF, pIL-6, and pCXCL1 are expression vectors carrying the cDNA encoding murine G-CSF, IL-6, and CXCL1, respectively. These plasmids were constructed by the insertion of cDNA into plasmid pcDNA3.1 (Invitrogen, Carlsbad, CA) in our laboratory [13].

\section{In vivo gene transfection}

Plasmids were prepared and analyzed as described previously [46]. Mice received the injection of plasmid DNA (in $100 \mu \mathrm{l}$ PBS) into the muscle tissue (i.m. injection) at the inoculation site or the injection of plasmid DNA via the tail vein (i.v. injection) using the hydrodynamics-based gene delivery technique [46].
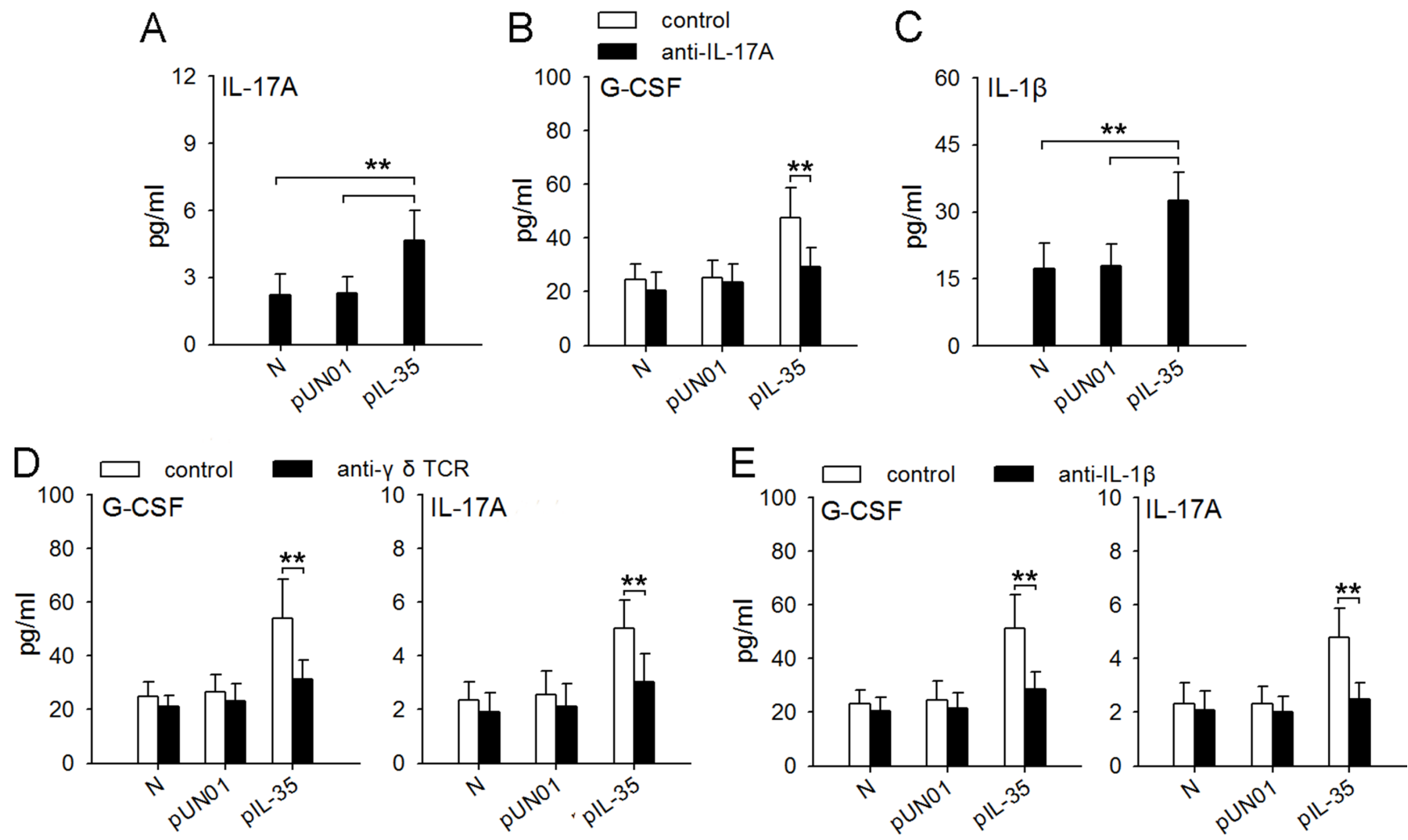

Figure 8: Macrophages/IL-1 $\beta / \gamma \delta$ T cells/IL-17 axis is involved in IL-35-induced expression of G-CSF in vivo. (A) ELISA analysis of IL-17A in the serum of naive mice, pUN01-mice and pIL-35-mice. (B) Mice were untreated or treated with anti-IL-17A antibody to neutralize IL-17A in vivo. G-CSF levels in serum of naive mice, pUN01-mice, and pIL-35-mice were detected by ELISA. (C) ELISA analysis of IL- $1 \beta$ in the serum of naive mice, pUN01-mice and pIL-35-mice. (D) After depletion of $\gamma \delta$ T cells with anti- $\gamma \delta$ TCR antibody in vivo, the levels of G-CSF and IL-17A in serum of naive mice, pUN01-mice, and pIL-35-mice were detected by ELISA. (E) Mice were untreated or treated with anti-IL-1 $\beta$ antibody to neutralize IL-1 $\beta$ in vivo. G-CSF and IL-17A levels in serum of naive mice, $\mathrm{pUN01-mice,}$ and pIL-35-mice were detected by ELISA. $* * p<0.01$. 


\section{Animal experiments and treatment protocols}

To acquire mice with in vivo expression of IL-35, mice received an i.m. injection of pIL-35 plasmids $(100 \mu \mathrm{g}$ of each per injection) in the left hind thigh (once every two days, four times); pUN01 plasmid was used as control. The mice were used for further experiment on d10 after first injection of plasmid. To acquire mice with in vivo expression of G-CSF and/or IL-6, mice received an i.m. injection of pG-CSF and/or pIL-6 plasmids (100 $\mu \mathrm{g}$ of each per injection) in the right hind thigh (once every two days, four times); pcDNA3.1 plasmid was used as control. Naive mice and the mice receiving plasmid injection were labeled by N, pUN01, pIL-35, pG, pI6, pG/pI6, and p3.1, respectively.

To recruit neutrophils to the inoculation site, mice were inoculated intramuscularly in the right hind thigh with $1 \times 10^{5} \mathrm{H} 22$ cells or $3 \times 10^{5} \mathrm{~B} 16$ cells. The mice in treatment groups received an i.m. injection, once every 2d, of pCXCL1 $(100 \mu \mathrm{g}$ per injection, day 1 to day 5 after tumor cell inoculation). The p3.1 plasmid was used as control. Tumors were dissected and weighed on d10 after tumor cell inoculation.

In co-inoculation test, mice were inoculated intramuscularly in the right hind thigh with $\mathrm{H} 22$ or B16 cells, mixed with $1 \times 10^{6}$ neutrophils. Tumors were dissected and weighed on d10 after tumor cell inoculation.

In intra-tumor injection test, the mice with palpable tumor were randomly divided into several groups. $1 \times 10^{6}$ neutrophils or equal volume of PBS ( $50 \mu \mathrm{l})$ were carefully injected to tumor, once a day for three times. Tumors were dissected on $\mathrm{d} 3$ after last injection for analysis of microvessel density.

To analyze the neutrophils in tumor tissues, mice were inoculated intramuscularly in the right hind thigh with H22 cells or B16 cells. For detecting neutrophils by flow cytometry, single-cell suspensions of tumors were prepared. In brief, Tumors were harvested from mice, minced, and digested with $2 \mathrm{mg} / \mathrm{ml}$ DNase I (Sigma, St. Louis, MO) and $4 \mathrm{mg} / \mathrm{ml}$ collagenase type IV (Sigma) at $37^{\circ} \mathrm{C}$ for $1 \mathrm{~h}$. After a PBS washing, cell suspensions were filtrated with a 200-mesh sieve for subsequent flow cytometry.

\section{Cytokine neutralization and $\gamma \delta \mathrm{T}$ cell depletion in vivo}

For cytokine (IL-17A or IL-1 $\beta$ ) neutralization experiments, mice were injected intraperitoneally with $50 \mu \mathrm{g}$ twice weekly for anti-IL-17A (Clone 50104; R\&D Systems), or $50 \mu \mathrm{g}$ twice weekly anti-IL-1 $\beta$ (clone B122; BioXCell). To deplete $\gamma \delta \mathrm{T}$ cells in vivo, mice were injected intraperitoneally with an initial $400 \mu \mathrm{g}$ followed by $100 \mu \mathrm{g}$ twice weekly for anti- $\gamma \delta$ TCR (clone GL3; R\&D Systems). Control mice received equal amounts of isotype control antibodies or equal volumes of PBS.

\section{Recruitment of neutrophils to peritoneal cavity}

To acquire CXCL1-expressing hepatocytes, mice received i.v. injection of pCXCL1 plasmid $(200 \mu \mathrm{g}$ per mouse). $12 \mathrm{~h}$ later, hepatocytes were prepared from liver by two-step collagenase perfusion technique [13]. To recruit neutrophils to peritoneal cavity, CXCL1-expressing hepatocytes were injected to peritoneal cavity of mice $\left(3 \times 10^{5}\right.$ per mouse) $.12 \mathrm{~h}$ later, the peritoneal cells were harvested for the isolation of neutrophils.

\section{Isolation of neutrophils}

Murine neutrophils were isolated from bone marrow cells or peritoneal cells as described previously [13]. Briefly, the cells were washed once in HBSS media. Cells were separated by centrifugation over a 3 layer discontinuous Percoll gradient (54\%/64\%/72\% for bone marrow cells and $54 \% / 64 \% / 80 \%$ for peritoneal cells). The dense band at $64 \% / 72 \%$ or $64 \% / 80 \%$ interface was collected as neutrophil fractions. Purity of isolated neutrophils was validated by flow cytometry and only samples greater than $90 \%$ purity was used (Supplementary Figure 6).

\section{Generation of murine bone marrow-derived macrophages}

Murine bone marrow derived macrophages were obtained according to the protocol in previous publication [47]. Bone marrow cell suspensions were cultured in the DMEM medium supplemented with $10 \%$ fetal calf serum, $1 \%$ Penicillin/Streptomycin and $10 \mathrm{U} / \mathrm{ml}$ recombinant murine M-CSF (PepProTech). Macrophages were then harvested on day 7 for subsequent cell stimulation assays.

\section{Other methods}

Other methods were performed using standard protocols, including cell transfection, flow cytometry and intracellular staining, assay of gene expression by realtime RT-PCR, immunohistochemistry, MMP-9 assay, Western blot assay, ELISA analysis, T cell proliferation assay. See Supplemental Methods for details.

\section{Statistical analysis}

Results were expressed as mean value $\pm \mathrm{SD}$ and interpreted by one-way ANOVA. Differences were considered statistically significant when $P<0.05$.

\section{ACKNOWLEDGMENTS AND FUNDING}

We thank Zhi-Hui Liang, Hui-Fen Zhu and WenHong $\mathrm{Lu}$ for technical assistance. 


\section{CONFLICTS OF INTEREST}

The authors declare that there are no conflicts of interest to disclose.

\section{REFEERNCES}

1. Candido J, Hagemann T. Cancer-related inflammation. J Clin Immunol. 2013; 33:S79-84.

2. Olson BM, Sullivan JA, Burlingham WJ. Interleukin 35: a key mediator of suppression and the propagation of infectious tolerance. Front Immunol. 2013; 4:315.

3. Niedbala W, Wei XQ, Cai B, Hueber AJ, Leung BP, McInnes IB, Liew FY. IL-35 is a novel cytokine with therapeutic effects against collagen-induced arthritis through the expansion of regulatory $\mathrm{T}$ cells and suppression of Th17 cells. Eur J Immunol. 2007; 37:3021-3029.

4. Whitehead GS, Wilson RH, Nakano K, Burch LH, Nakano H, Cook DN. IL-35 production by inducible costimulator (ICOS)-positive regulatory $\mathrm{T}$ cells reverses established IL-17-dependent allergic airways disease. J Allergy Clin Immunol. 2012; 129:207-215 e201-205.

5. Thiolat A, Denys A, Petit M, Biton J, Lemeiter D, Herve R, Lutomski D, Boissier MC, Bessis N. Interleukin-35 gene therapy exacerbates experimental rheumatoid arthritis in mice. Cytokine. 2014; 69:87-93.

6. Kuo J, Nardelli DT, Warner TF, Callister SM, Schell RF. Interleukin-35 enhances Lyme arthritis in Borreliavaccinated and -infected mice. Clin Vaccine Immunol. 2011; 18:1125-1132.

7. Turnis ME, Sawant DV, Szymczak-Workman AL, Andrews LP, Delgoffe GM, Yano H, Beres AJ, Vogel P, Workman CJ, Vignali DA. Interleukin-35 Limits Anti-Tumor Immunity. Immunity. 2016; 44:316-329.

8. Nicholl MB, Ledgewood CL, Chen X, Bai Q, Qin C, Cook KM, Herrick EJ, Diaz-Arias A, Moore BJ, Fang Y. IL35 promotes pancreas cancer growth through enhancement of proliferation and inhibition of apoptosis: evidence for a role as an autocrine growth factor. Cytokine. 2014; 70:126-133.

9. Zeng JC, Zhang Z, Li TY, Liang YF, Wang HM, Bao JJ, Zhang JA, Wang WD, Xiang WY, Kong B, Wang ZY, $\mathrm{Wu} \mathrm{BH}$, Chen XD, et al. Assessing the role of IL-35 in colorectal cancer progression and prognosis. Int J Clin Exp Pathol. 2013; 6:1806-1816.

10. Jin L, Xu X, Ye B, Pan M, Shi Z, Hu Y. Elevated serum interleukin-35 levels correlate with poor prognosis in patients with clear cell renal cell carcinoma. Int J Clin Exp Med. 2015; 8:18861-18866.

11. Gu X, Tian T, Zhang B, Liu Y, Yuan C, Shao L, Guo Y, Fan K. Elevated plasma interleukin-35 levels predict poor prognosis in patients with non-small cell lung cancer. Tumour Biol. 2015; 36:2651-2656.

12. Sionov RV, Fridlender $Z G$, Granot $Z$. The multifaceted roles neutrophils play in the tumor microenvironment. Cancer Microenviron. 2015; 8:125-158.
13. Yan B, Wei JJ, Yuan Y, Sun R, Li D, Luo J, Liao SJ, Zhou YH, Shu Y, Wang Q, Zhang GM, Feng ZH. IL-6 cooperates with G-CSF to induce protumor function of neutrophils in bone marrow by enhancing STAT3 activation. J Immunol. 2013; 190:5882-5893.

14. Fridlender ZG, Sun J, Kim S, Kapoor V, Cheng G, Ling L, Worthen GS, Albelda SM. Polarization of tumor-associated neutrophil phenotype by TGF-beta: "N1" versus "N2" TAN. Cancer cell. 2009; 16:183-194.

15. Sun R, Luo J, Li D, Shu Y, Luo C, Wang SS, Qin J, Zhang GM, Feng ZH. Neutrophils with protumor potential could efficiently suppress tumor growth after cytokine priming and in presence of normal NK cells. Oncotarget. 2014; 5:12621-12634. doi: 10.18632/oncotarget.2181.

16. Wang Z, Liu JQ, Liu Z, Shen R, Zhang G, Xu J, Basu S, Feng Y, Bai XF. Tumor-derived IL-35 promotes tumor growth by enhancing myeloid cell accumulation and angiogenesis. J Immunol. 2013; 190:2415-2423.

17. Collison LW, Chaturvedi V, Henderson AL, Giacomin PR, Guy C, Bankoti J, Finkelstein D, Forbes K, Workman CJ, Brown SA, Rehg JE, Jones ML, Ni HT, et al. IL-35mediated induction of a potent regulatory $\mathrm{T}$ cell population. Nat Immunol. 2010; 11:1093-1101.

18. Wang RX, Yu CR, Dambuza IM, Mahdi RM, Dolinska MB, Sergeev YV, Wingfield PT, Kim SH, Egwuagu CE. Interleukin-35 induces regulatory $\mathrm{B}$ cells that suppress autoimmune disease. Nat Med. 2014; 20:633-641.

19. Kolaczkowska E, Kubes P. Neutrophil recruitment and function in health and inflammation. Nat Rev Immunol. $2013 ; 13: 159-175$.

20. Christoffersson G, Vagesjo E, Vandooren J, Liden M, Massena S, Reinert RB, Brissova M, Powers AC, Opdenakker G, Phillipson M. VEGF-A recruits a proangiogenic MMP-9-delivering neutrophil subset that induces angiogenesis in transplanted hypoxic tissue. Blood. 2012; 120:4653-4662.

21. Sceneay J, Chow MT, Chen A, Halse HM, Wong CS, Andrews DM, Sloan EK, Parker BS, Bowtell DD, Smyth MJ, Moller A. Primary tumor hypoxia recruits $\mathrm{CD}_{11 \mathrm{~b}} / \mathrm{Ly} 6 \mathrm{Cmed} / \mathrm{Ly} 6 \mathrm{G}^{+}$immune suppressor cells and compromises NK cell cytotoxicity in the premetastatic niche. Cancer Res. 2012; 72:3906-3911.

22. Tazzyman S, Lewis CE, Murdoch C. Neutrophils: key mediators of tumour angiogenesis. Int J Exp Pathol. 2009; 90:222-231.

23. Liang W, Ferrara N. The complex role of neutrophils in tumor angiogenesis and metastasis. Cancer Immunol Res. 2016; 4:83-91.

24. Coffelt SB, Kersten K, Doornebal CW, Weiden J, Vrijland K, Hau CS, Verstegen NJ, Ciampricotti M, Hawinkels LJ, Jonkers J, de Visser KE. IL-17-producing gammadelta T cells and neutrophils conspire to promote breast cancer metastasis. Nature. 2015; 522:345-348.

25. Munder M, Mollinedo F, Calafat J, Canchado J, GilLamaignere C, Fuentes JM, Luckner C, Doschko G, 
Soler G, Eichmann K, Muller FM, Ho AD, Goerner M, Modolell M. Arginase I is constitutively expressed in human granulocytes and participates in fungicidal activity. Blood. 2005; 105:2549-2556.

26. Rotondo R, Bertolotto M, Barisione G, Astigiano S, Mandruzzato S, Ottonello L, Dallegri F, Bronte V, Ferrini S, Barbieri O. Exocytosis of azurophil and arginase 1-containing granules by activated polymorphonuclear neutrophils is required to inhibit $\mathrm{T}$ lymphocyte proliferation. J Leukoc Biol. 2011; 89:721-727.

27. Xu Z, Wang BR, Wang X, Kuang F, Duan XL, Jiao XY, Ju G. ERK1/2 and p38 mitogen-activated protein kinase mediate iNOS-induced spinal neuron degeneration after acute traumatic spinal cord injury. Life Sci. 2006; 79:1895-1905.

28. Ratajczak-Wrona W, Jablonska E, Garley M, Jablonski J, Radziwon P, Iwaniuk A. The role of MAP kinases in the induction of iNOS expression in neutrophils exposed to NDMA: the involvement transcription factors. Adv Med Sci. 2013; 58:265-273.

29. Nakamae-Akahori M, Kato T, Masuda S, Sakamoto E, Kutsuna H, Hato F, Nishizawa Y, Hino M, Kitagawa S. Enhanced neutrophil motility by granulocyte colonystimulating factor: the role of extracellular signal-regulated kinase and phosphatidylinositol 3-kinase. Immunology. 2006; 119:393-403.

30. Fukuzono S, Kato T, Fujita H, Watanabe N, Kitagawa S. Granulocyte colony-stimulating factor negatively regulates Toll-like receptor agonist-induced cytokine production in human neutrophils. Arch Biochem Biophys. 2010; 495:144-151.

31. Bluyssen HA, Rastmanesh MM, Tilburgs C, Jie K, Wesseling S, Goumans MJ, Boer P, Joles JA, Braam B. IFN gamma-dependent SOCS3 expression inhibits IL-6induced STAT3 phosphorylation and differentially affects IL-6 mediated transcriptional responses in endothelial cells. Am J Physiol Cell physiol. 2010; 299:C354-362.

32. Filkova M, Vernerova Z, Hulejova H, Prajzlerova K, Veigl D, Pavelka K, Vencovsky J, Senolt L. Proinflammatory effects of interleukin-35 in rheumatoid arthritis. Cytokine. 2015; 73:36-43.

33. Dittrich A, Hessenkemper W, Schaper F. Systems biology of IL-6, IL-12 family cytokines. Cytokine Growth Factor Rev. 2015; 26:595-602.

34. Cetean S, Cainap C, Constantin AM, Cainap S, Gherman A, Oprean L, Hangan A, Oprean R. The importance of the granulocyte-colony stimulating factor in oncology. Clujul Med. 2015; 88:468-472.

35. Ley K, Smith E, Stark MA. IL-17A-producing neutrophilregulatory Tn lymphocytes. Immunol Res. 2006; 34:229-242.

36. Wu H, Li P, Shao N, Ma J, Ji M, Sun X, Ma D, Ji C. Aberrant expression of Treg-associated cytokine IL-35 along with IL-10 and TGF-beta in acute myeloid leukemia. Oncology letters. 2012; 3:1119-1123.

37. Wang Z, Liu JQ, Liu Z, Shen R, Zhang G, Xu J, Basu S, Feng Y, Bai XF. Tumor-derived IL-35 promotes tumor growth by enhancing myeloid cell accumulation and angiogenesis. J Immunol. 2013; 190:2415-2423.

38. Bekes EM, Schweighofer B, Kupriyanova TA, Zajac E, Ardi VC, Quigley JP, Deryugina EI. Tumor-recruited neutrophils and neutrophil TIMP-free MMP-9 regulate coordinately the levels of tumor angiogenesis and efficiency of malignant cell intravasation. Am J Pathol. 2011; 179:1455-1470.

39. Shojaei $\mathrm{F}, \mathrm{Wu} \mathrm{X}$, Zhong $\mathrm{C}$, Yu L, Liang XH, Yao J, Blanchard D, Bais C, Peale FV, van Bruggen N, Ho C, Ross J, Tan M, et al. Bv8 regulates myeloid-cell-dependent tumour angiogenesis. Nature. 2007; 450:825-831.

40. Cantarella G, Risuglia N, Dell'eva R, Lempereur L, Albini A, Pennisi G, Scoto GM, Noonan DN, Bernardini R. TRAIL inhibits angiogenesis stimulated by VEGF expression in human glioblastoma cells. Br J Cancer. 2006; 94:1428-1435.

41. de Miguel D, Lemke J, Anel A, Walczak H, MartinezLostao L. Onto better TRAILs for cancer treatment. Cell Death Differ. 2016; 23:733-747.

42. Shojaei F, Wu X, Qu X, Kowanetz M, Yu L, Tan M, Meng YG, Ferrara N. G-CSF-initiated myeloid cell mobilization and angiogenesis mediate tumor refractoriness to anti-VEGF therapy in mouse models. Proc Natl Acad Sci U S A. 2009; 106:6742-6747.

43. Templeton AJ, McNamara MG, Seruga B, Vera-Badillo FE, Aneja P, Ocana A, Leibowitz-Amit R, Sonpavde G, Knox JJ, Tran B, Tannock IF, Amir E. Prognostic role of neutrophilto-lymphocyte ratio in solid tumors: a systematic review and meta-analysis. J Natl Cancer Inst. 2014; 106:dju124.

44. Long J, Zhang X, Wen M, Kong Q, Lv Z, An Y, Wei XQ. IL-35 over-expression increases apoptosis sensitivity and suppresses cell growth in human cancer cells. Biochem Biophys Res Commun. 2013; 430:364-369.

45. Pylayeva-Gupta Y. Molecular pathways: interleukin-35 in autoimmunity and cancer. Clin Cancer Res. 2016; 22:49734978.

46. Geng H, Zhang GM, Li D, Zhang H, Yuan Y, Zhu HG, Xiao H, Han LF, Feng ZH. Soluble form of T cell Ig mucin 3 is an inhibitory molecule in T cell-mediated immune response. J Immunol. 2006; 176:1411-1420.

47. Zhang X, Goncalves R, Mosser DM. The isolation and characterization of murine macrophages. Curr Protoc Immunol. 2008; Chapter 14:Unit 14.1.

48. Weidner N. Intratumor microvessel density as a prognostic factor in cancer. Am J Pathol. 1995; 147:9-19.

49. Liu Y, Huang B, Yuan Y, Gong W, Xiao H, Li D, Yu ZR, Wu FH, Zhang GM, Feng ZH. Inhibition of hepatocarcinoma and tumor metastasis to liver by gene therapy with recombinant CBD-HepII polypeptide of fibronectin. Int J Cancer. 2007; 121:184-192.

50. Gong W, Zhang GM, Liu Y, Lei Z, Li D, Yuan Y, Huang B, Feng ZH. IFN-gamma withdrawal after immunotherapy potentiates B16 melanoma invasion and metastasis by intensifying tumor integrin alphavbeta3 signaling. Int $\mathrm{J}$ Cancer. 2008; 123:702-708. 